\title{
DESIGN E EDUCAÇÃO: PROJETO DE UM MATERIAL DIDÁTICO PARA DEFICIENTES VISUAL
}

\author{
Pedro Ryô de Landim y Goya \\ PPG em Educação para Ciência - FC - UNESP/Bauru \\ p_goya@hotmail.com \\ Mariano Lopes de Andrade Neto \\ NUPECAM - PPG em Design - FAAC - UNESP/Bauru \\ mlaneto@gmail.com \\ Paula da Cruz Landim \\ NUPECAM - PPG em Design - FAAC - UNESP/Bauru \\ paula@faac.unesp.br
}

Resumo: Desde sua promulgação em 1996, a Lei de Diretrizes e Bases da Educação Nacional, garante o acesso de alunos com Necessidades Educacionais Especiais ao ensino regular público. Entretanto, o processo de inclusão desses alunos tem muito a se desenvolver, uma vez que os recursos didáticos específicos disponíveis são limitados, quando existentes. Além disso, a grande maioria dos profissionais da escola pública não tem formação especializada para atender a esse público, o que gera dificuldades tanto para a aprendizagem do aluno, como para a ação do docente nas atividades de ensino. Assim, o desenvolvimento de materiais que auxiliem na inclusão de alunos com deficiência é uma demanda atual e ainda pouco atendida. Portanto, este trabalho relata o desenvolvimento do projeto de um material didático inclusivo para o ensino de Ciências e Biologia, o qual integra alunos com necessidades visuais especiais. Sendo o material didático inclusivo idealizado pela parceria de um docente do ensino básico em parceria com um designer, considerando a experiência do professor como usuário na elaboração projeto por meio de etapas comuns aos métodos de Design. Este projeto será disponibilizado aos docentes para sua confecção em aula. Com isso espera-se contribuir para a Educação e Inclusão com uma ação cotidiana ao Design, e promover reflexões sobre as possibilidades de mais projetos nesse sentido.

Palavras-chave: Design, Educação, Material Didático, Deficientes Visuais.

Abstract: Since its enactment in 1996, the National Educational Bases and Guidelines Law, ensures access of students with Special Educational Needs to regular public school. However, the process of inclusion of these 
students has a lot to develop, since the specific teaching resources available are limited, if any. In addition, the vast majority of public school professionals do not have specialized training to serve this public, which creates difficulties for the student learning and for the action of the teacher in educative activities. Thus, the development of materials that assist in the inclusion of students with disabilities is a current demand and poorly attended. Therefore, this work describes the design development of an inclusive didactic material for the teaching of science and biology, which integrates students with visual impairment. Being the inclusive didactic materials designed by the partnership of a teacher of elementary education in collaboration with a designer, considering the experience of the teacher as a user in the project preparation through common steps to the Design methods. This project will be available to teachers for their preparation in class. Therefore, we expect to contribute to the Education and Inclusion with a daily action to design and promote reflection on the possibilities of more projects in this sense.

Keys-words: Design, Education, Didactic Material, Visual Impairment.

\section{INTRODUÇÃO}

Há muitos anos discute-se a inclusão social como um pré-requisito para os direitos e liberdades fundamentais à vida humana. Uma das ações para a efetiva inclusão consolida-se na perspectiva da educação inclusiva - El. No Brasil, a El se estabelece em termos legais com a Lei de Diretrizes e Bases da Educação Nacional LDBEN (BRASIL, 1996), baseada na Declaração de Salamanca, a qual tem por princípio que "Toda criança tem direito fundamental à educação, e deve ser dada a oportunidade de atingir e manter o nível adequado de aprendizagem" (UNESCO, 1994). Assim, a El busca a participação de todos ativamente em todas as atividades que a escola possa oferecer e é responsabilidade da coordenação da escola e do docente promovê-la.

Porém, muitos docentes não estão aptos a executar tal tarefa, em função de sua formação inicial e ou continuada e, após 18 anos da promulgação da LBDEN o processo de inclusão de alunos com deficiência no ensino regular ainda têm muito a se desenvolver. De acordo com Sant'ana (2005, p.2008), apesar da necessidade de preparação adequada dos agentes educacionais estar preconizada na Declaração de Salamanca (UNESCO, 1994) e na LBDEN (BRASIL, 1996) como fator fundamental para a $\mathrm{El}$, o que tem acontecido nos cursos de formação docente, em termos gerais, é a ênfase dada aos aspectos teóricos, com currículos distanciados da prática pedagógica, não proporcionando, por conseguinte, a capacitação necessária aos profissionais para o trabalho com a diversidade dos educandos.

Observando as dificuldades relatadas no ensino regular para a realidade inclusiva, em seu estudo com alunos deficientes visuais em uma aula de óptica Camargo et al. (2008, p.12) apresenta a comunicação como principal barreira para o aprendizado desses alunos. Durante a pesquisa o autor descreve que as dificuldades comunicacionais organizaram-se em torno de nove perfis linguisticos, sendo que a 
estrutura áudio-visual interdependente mostrou-se uma barreira comunicacional a ser superada, tanto pelo número de vezes em que foi identificada, quanto pela forma como organiza a veiculação de significados, esta se caracteriza pelo fato de veicular por meio de códigos auditivos e visuais interdependentes, significados ópticos vinculados às representações visuais, ou seja, os fenômenos visuais são explicados utilizando-se de recursos e exemplos visuais. O autor aponta "sem a utilização de canais comunicacionais adequados, alunos com deficiência visual encontrar-se-ão, do ponto de vista conceitual e procedimental, numa condição de exclusão no interior da sala de aula" (op cit., p. 12).

Portanto para se evitar situações que gerem mais dúvidas, novas práticas são necessárias, assim como a renovação de estratégias e recursos de ensino que favoreçam tal aprendizagem.

O material didático é um importante componente no ensino regular, assim como para a aprendizagem e desenvolvimento da sociabilidade dos educandos com necessidades educacionais especiais - NEE - com seus pares (ARAGÃO et al., 2008, p.1). Sendo muitas vezes um recurso essencial no processo de ensino e aprendizagem, auxiliando docentes nas estratégias didáticas aplicadas em aula.

Considerando o exposto, a partir da demanda identificada por um docente de Biologia, surgiu a proposta de um projeto em conjunto entre tal professor e um designer, no qual foi desenvolvido um material didático para deficientes visuais - DV, visando auxiliar no ensino de conteúdos de Biologia. Portanto, este trabalho teve como objetivo relatar a experiência e os resultados dessa parceria. Para o estudo, realizou-se um breve levantamento teórico sobre a educação inclusiva no Brasil, focado em sua regulamentação, em especial no tocante aos recursos didáticos. E também de pesquisas sobre a produção de recursos didáticos inclusivos (CAMARGO; NARDI, 2007; PEREIRA, 2012; LOPES, ALMEIDA, AMADO, 2014). Em seguida, a elaboração do projeto de material didático deu-se a partir de dados obtidos nos estudos de Teodoro (2014) e de Miranda (2014), nos quais se buscou identificar os conteúdos de Ciências e Biologia cujos alunos com NEE e docentes encontravam maiores dificuldades no processo de ensino-aprendizagem. Para o desenvolvimento da proposta de projeto foram utilizadas adaptações de etapas comuns ao escopo de métodos de Design.

\section{REFERENCIAL TEÓRICO}

\subsection{Educação inclusiva no Brasil}

A educação especial foi definida no artigo 58 da LDBEN 9394/96 como "modalidade de ensino destinada aos educandos com necessidades especiais, preferencialmente na rede regular de ensino" (BRASIL, 1996). Ela estabeleceu que o sistema de ensino deveria assegurar a estes educandos: "currículos, métodos, técnicas, recursos educativos e organização específica, para atender às suas necessidades".

Passados 18 anos, houve mudanças na política de educação especial brasileira, sendo importante destacar a adoção da perspectiva inclusiva, a qual ganhou definições particulares relacionadas aos sujeitos que constituem o público alvo dessas ações àqueles com deficiências, altas habilidades e transtornos globais de desenvolvimento (GARCIA, 2013, p.101).

Mais recentemente, a educação inclusiva foi entendida como uma ação política, cultural, social e pedagógica, a qual visa garantir o direito de todos os alunos 
de estarem juntos, aprendendo e participando, sem nenhum tipo de discriminação (BRASIL, 2007, p.1). Fato que ocasionou uma nova postura na escola regular, a qual teve de incorporar ações e práticas educativas que atendam a toda diversidade de alunos.

Garcia (2013, p.104-105) destaca que para a compreensão da política de educação especial recente no Brasil, é necessário conhecer alguns documentos: a introdução da educação especial na educação básica, pela Resolução n.2/2001 (BRASIL, 2001); as redefinições da Política Nacional de Educação Especial na Perspectiva Inclusiva (BRASIL, 2007); e a consolidação de tal política, regulada pelo Decreto n.6.571/2008 (BRASIL, 2008) e pela Resolução n.4/2009 (BRASIL, 2009).

O primeiro documento (BRASIL, 2001, p.1) "institui as Diretrizes Nacionais para a educação de alunos que apresentem necessidades educacionais especiais, na Educação Básica, em todas as suas etapas e modalidades". Nele constam informações sobre o ingresso dos educandos no sistema de ensino regular público e privado; sobre o entendimento sobre educação especial; sobre o perfil dos educandos atendidos; os procedimentos para sua identificação; as obrigações e ações das escolas e dos profissionais de ensino envolvidos. Tais diretrizes regularizam o cenário da educação especial nacional. O segundo, referente à política de educação de 2007, neste documento as políticas de educação especial, apresentadas em 2001, são redefinidas e agora entendidas como inclusivas. O Decreto 6.571 (BRASIL, 2008, p.1) descreve o atendimento educacional especializado como "conjunto de atividades, recursos de acessibilidade e pedagógicos organizados institucionalmente, prestado de forma complementar ou suplementar à formação dos alunos no ensino regular" e dispõe sobre seus objetivos e procedimentos. A Resolução de 2009 (BRASIL, 2009, p.1) "Institui Diretrizes Operacionais para o Atendimento Educacional Especializado na Educação Básica, modalidade Educação Especial”, estabelecendo as diretrizes para a efetiva implementação do Decreto 6.571. No entanto, o Decreto 6.571 foi revogado em 2011 pelo Decreto no 7.611. Neste último são dispostos os deveres do Estado para com os educandos com NEE, os objetivos do Atendimento Educacional Especializado (AEE), e o apoio técnico e financeiro do Estado às instituições. O Decreto de 2011 mantém as principais disposições e normas anteriores, suprimindo alguns detalhamentos relativos às responsabilidades técnicas e financeiras.

Em suma, entende-se que o educando foi incluído em turmas comuns, e passou a contar com atendimento, serviços e recursos especializados. Evidenciando-se a revisão do conceito de educação especial e sua articulação com a perspectiva de inclusão escolar e de não segregação dos indivíduos com necessidades especiais e/ou com deficiência. Por outro lado, Garcia (2013, p.106) destaca que a redefinição da Educação Especial deixou de identificá-la com uma proposta pedagógica, para centrarse na disponibilização de recursos e serviços. Uma proposição muito distante da realidade das atuais salas de aula, nas quais os docentes não contam com recursos didáticos específicos, e muito menos têm formação e muitas vezes tempo ou condições para um atendimento especial.

Ainda sobre as dificuldades para a efetivação da proposta inclusiva, De Vitta et al. (2010, p.417) apontam que, entre os desafios, estão: a não formação de práticas educacionais essenciais à promoção da mesma; ausência de auxílio técnico pedagógico especializado, de espaço físico não adaptado e material didático inadequado; dificuldade no acompanhamento de conteúdos ministrados; desconhecimento sobre a 
deficiência do aluno e, portanto a não adequação de currículos e estratégias de aula, resultando na exclusão do aluno de atividades, além da falta de preparo/formação do professor da classe regular.

Nessa perspectiva de inclusão dos educandos com NEE no ensino regular é dever da escola se adaptar aos alunos e não os alunos terem que se adaptar à escola. Assim, quando um aluno apresenta dificuldades de aprendizagem por qualquer motivo, o docente deve aprofundar-se com relação às características desse aluno, para que possa diagnosticar problemas para ajustar suas práticas de ensino (BRAZ et al. 2012, p.6971). E as informações trazidas por essas experiências podem contribuir para a investigação e elaboração de estratégias e recursos didáticos para as mais diversas necessidades.

Por exemplo, no caso de educandos com diferentes graus de deficiência visual, nos Parâmetros Curriculares Nacionais - PCN (BRASIL, 1998) encontram-se adaptações curriculares para o emprego de sistemas alternativos de comunicação adequados às possibilidades do aluno, como: posicionamento do educando próximo ao docente em sala favorecendo a audição; disposição do mobiliário para facilitar o deslocamento; explicações verbais sobre todo o material apresentado de maneira visual; adaptação de materiais escritos de uso comum - tamanho das letras, relevo, texturas, softwares específicos, material em Braille; material didático e de avaliação adaptados; entre outras medidas.

Cabe, portanto, principalmente aos docentes encontrar alternativas às práticas pedagógicas tradicionais, visando à inclusão dos alunos com DV. Neste sentido, o escopo do Design pode contribuir no desenvolvimento e produção de materiais didáticos adequados como um importante auxiliar na prática educativa inclusiva.

\subsection{Desenvolvimento de materiais didáticos inclusivos}

Os materiais didáticos são entendidos como recursos necessários e facilitadores da aprendizagem (YOSHIKAWA, 2010, p. 47), devendo-se considerar as alternativas de ensino apropriadas a cada tipo de conteúdo, às necessidades específicas do contexto educativo, assim como, às necessidades individuais dos alunos. Tais materiais

(...) devem ser diversos e diversificáveis, para que, como peças de uma construção, permitam a cada professor elaborar seu projeto específico de intervenção adaptado às necessidades de sua realidade educacional e à sua personalidade. Quanto mais diversos e mais diversificáveis forem os materiais, mais fácil será a elaboração de propostas singulares (ZABALA, 1998 apud YOSHIKAWA, 2010, p. 47).

Martí (1999, p.37) apresenta diversos recursos didáticos que podem ser usados no ensino de alunos com NEE. No caso de deficientes visuais, ele propõe o estimulo do tato e da audição, com a utilização de materiais com diferentes texturas, o uso de som e de explicações verbais para que o aluno passe a compreender melhor o conteúdo. Para o autor, é necessário haver mais materiais didáticos multissensoriais.

Batista (2005, p.13) apud Yoshikawa (2010, p.49) considera que no ensino voltado aos DV a noção de representação demanda maior atenção. Como no caso de conceitos abstratos do conteúdo de Ciências como gravidade, planetas, células, evolução, cadeia alimentar, fisiologia, entre outros. Geralmente, utiliza-se nesses casos o emprego de recursos táteis como maquetes e modelos tridimensionais, 
disponibilizados nas escolas. Entretanto, Vaz et al. (2012, p.85) afirma que para a pessoa com deficiência visual, os materiais didáticos necessitam estar adequados ao seu referencial perceptual, que é desconhecido aos videntes. Para os autores, o docente, ao utilizar recursos específicos, precisa desenvolver estratégias pedagógicas inclusivas, adequadas a toda turma, e ainda que favoreçam o desenvolvimento da criança com DV.

Os autores (op cit., p.21) elaboraram um modelo de síntese de proteínas nas células animais e compararam a apropriação do conhecimento com alunos videntes e não videntes. E encontraram que tais recursos foram significativos para o ensino do conteúdo. As adaptações realizadas nos materiais possibilitaram o uso de todos os alunos videntes e não videntes.

A aproximação do Design com a área de Educação revela as inúmeras possibilidades de atuação para o designer, "reafirmando a vocação interdisciplinar desta área de conhecimento" (COUTO e PORTUGAL, 2011, p.01). Em todo projeto de design há uma busca de equilíbrio entre interesses e necessidades do usuário, no caso do projeto e confecção de recursos didáticos é necessário atender aos diferentes tipos de público: educandos com DV e docentes interessados no AEE.

A concepção e o planejamento de materiais didáticos, geralmente, são determinados pelo aspecto visual e por consequência, como afirmam Coutinho, Lopes e Cadena (2011, p.6) "a combinação texto/imagem/esquema proporciona maior participação do aluno na aprendizagem, por meio da análise dessa relação". Sendo que a maioria dos recursos disponíveis segue essa lógica.

Assim, o projeto de recursos inclusivos, ou seja, que não apenas considerem as limitações dos alunos com DV, mas que também mantenham o interesse dos alunos videntes é um desafio aos novos recursos didáticos em desenvolvimento. A produção destes materiais auxiliada pela tecnologia - como computadores, softwares, impressoras tridimensionais, entre outros - é uma possibilidade, sendo que já existem equipamentos para tanto. Entretanto, no que tange ao ensino público, o uso de equipamentos de tecnologia recente ainda não é regra em todos os lugares. Outra condição do projeto é o envolvimento do docente na produção do material, considerando-se a "concepção de material como o elo entre o conhecimento, realidade sócio-educacional e aluno, utilizado no ensino como forma de contribuir para a aprendizagem" (BORGES, 2000, p. 87). Ainda segundo o autor, ao montar seu próprio material, o docente passa a planejar e decidir sobre sua própria prática e busca alternativas para uma aprendizagem mais significativa, permitindo uma reflexão crítica sobre vários aspectos do ensino-aprendizagem.

Partindo dos pressupostos apresentados, a elaboração do recurso didático teve como prioridade o processo artesanal, possibilitando a divulgação do projeto e reprodução pelos docentes. Também por isso, além da técnica, tanto os componentes materiais, como a sua disposição, são de uso cotidiano e de fácil acesso.

\section{MATERIAIS E MÉTODOS}

O desenvolvimento do projeto foi realizado em seis etapas: pesquisa; requisitos; geração; análise; confecção; instruções. A primeira foi uma pesquisa bibliográfica de caráter exploratório, na qual os resultados dos estudos de Miranda (2014) e Teodoro (2014) foram complementados, formando a base teórica dos conteúdos e das estratégias didáticas a serem adotados no material proposto. 
Os dados obtidos também serviram de referência para determinar os requisitos do projeto. Tais informações foram organizadas - pelo docente de biologia juntamente com o designer - nos seguintes itens: objetivo, caracterização do público alvo, características obrigatórias, limitações do projeto, meios de produção. Em seguida, iniciou-se a fase de geração de propostas, na qual os participantes discutiram as prováveis soluções apresentadas verbalmente ou por meio de desenhos esquemáticos. Esta fase foi coordenada pelo docente, por sua maior familiaridade com o conteúdo. As alternativas desenvolvidas foram discutidas mediante os requisitos do projeto. A proposta considerada mais adequada na etapa de análise foi confeccionada. Nesta etapa avaliou-se a facilidade de produção, o desempenho dos materiais e, principalmente, as possibilidades de interação entre alunos e docente. Por fim, foram desenvolvidas as instruções e recomendações do projeto do material didático a ser confeccionado pelos docentes.

\subsection{Resultados e discussões}

No detalhamento dos requisitos, o objetivo consta como o desenvolvimento do projeto de um recurso didático que auxilie o ensino de alunos com DV. Mais especificamente, a "Teia Alimentar" foi selecionada como o conteúdo para a abordagem no material didático, trata-se de um conceito de Ecologia indicado como de maior dificuldade de aprendizagem nos estudos de Miranda (2014) e Teodoro (2014). Tal conteúdo está presente tanto no currículo do ensino fundamental quanto no do ensino médio, nas disciplinas de Ciências e Biologia respectivamente. E devido a grande amplitude de idade e interesses, optou-se por desenvolver um material que atendesse aos alunos do ensino básico.

O projeto teve como características obrigatórias o desenvolvimento de um material multissensorial, adequação ao uso por toda a turma - alunos não videntes e videntes -, e a escolha de um processo artesanal. Quanto às limitações, o baixo custo total, a complexidade dos procedimentos de confecção e os materiais selecionados deveriam - os quais ser comuns ao ambiente escolar -, foram os principais pontos destacados. Por fim, os meios de produção foram selecionados a partir das diretrizes anteriores.

Dentre as alternativas de projeto criadas foi escolhida a que envolveu a construção física de uma Teia Alimentar. Nela foram elaborados cartões com imagens dos diferentes seres vivos - representando produtores, consumidores e decompositores. Estes cartões deveriam possuir algum recurso tátil para identificação da imagem pelos alunos com DV. Depois de prontos, eles seriam ligados para a confecção da teia. Partindo desse conceito, foi confeccionado um primeiro protótipo pelo docente (figura 1). No primeiro modelo construído, as imagens possuíam apenas linhas, as quais foram destacadas com relevo por meio de tinta plástica. Os cartões foram padronizados em tamanho $A 6$ e colados em bases do mesmo tamanho de papel de alta gramatura. 

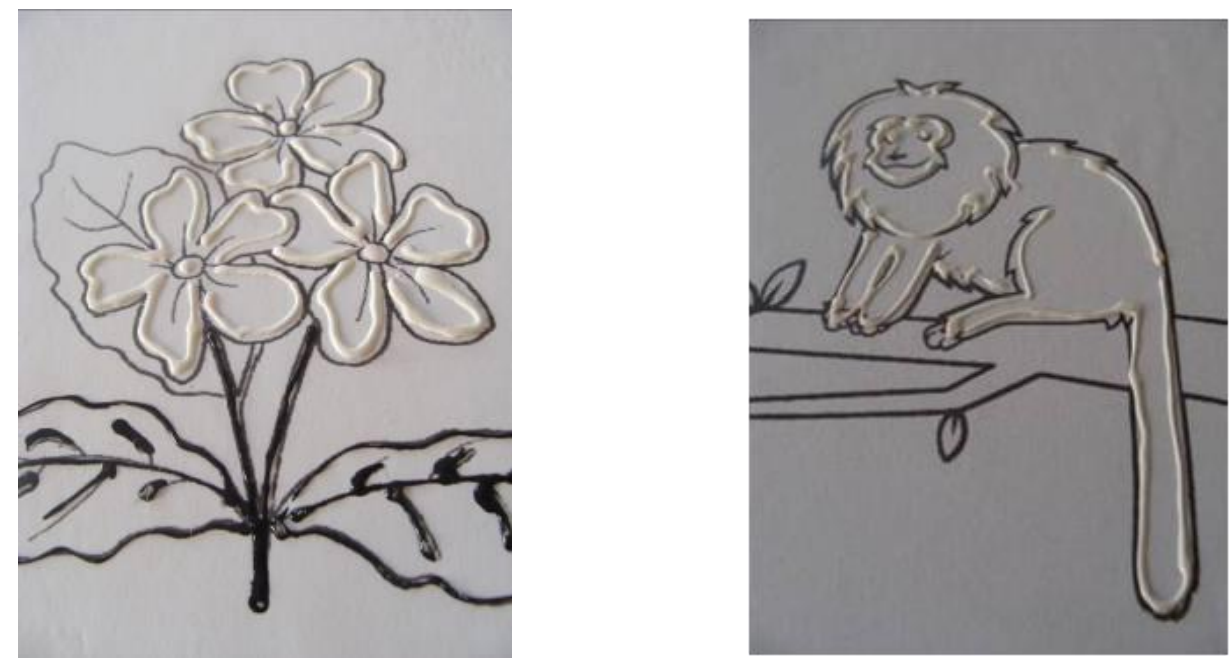

Figura 1 - Exemplos de alternativas confeccionadas

Fonte: Adaptado pelo autor, com base na pesquisa realizada

Com o modelo finalizado, o docente pode interagir com o material didático elaborando possíveis estratégias de ensino, como por exemplo: a distribuição aleatória dos cartões para que os próprios alunos construam a Teia; ou com a Teia já interligada, com seus fios cruzando a sala aleatoriamente, os alunos seriam convidados a seguir cada componente da cadeia, promovendo uma interação espacial entre os videntes e não videntes.

Aprovado o projeto pelo docente, o modelo foi revisto mediante as suas possibilidades construtivas de acordo com o escopo do Design. Primeiramente, quanto ao público, é importante considerar que existem vários tipos de baixa visão, o que torna complicado confeccionar materiais didáticos específicos para atender cada faixa desse público; por isso, o emprego de traços, texturas em alto relevo, e alto contraste de cores, pode ser uma resposta adequada à maioria dos deficientes visuais, tendo em vista as restrições de custo.

A elaboração do recurso didático escolhido pode ser totalmente artesanal, incluindo a criação das figuras em traço. A posterior sobreposição com o material aglutinante dispõe de variadas opções de matéria prima na própria escola, como: tinta plástica com alguma carga para reforçar texturas, cola branca com carga e corantes, barbantes tingidos colados, entres outros.

As limitações técnicas que devem constar nas instruções dizem respeito à maneira de produção e reprodução dos materiais didáticos táteis. Essas foram elaboradas a partir do conhecimento prático de Design: tamanho e proporções da imagem selecionada, uma vez que os detalhes muito pequenos e ângulos fechados podem ser distorcidos pela camada de aglutinante; também deve haver uma uniformidade de espessuras de traços; o papel usado deve ser mais estruturado para a impressão, com gramatura $90 \mathrm{~g} / \mathrm{m}^{2}$, para resistir a várias manipulações em aula.

Por fim, as instruções do projeto contêm informações sobre as características necessárias aos materiais utilizados, os procedimentos de construção, além de sugestões de estratégias didáticas. No entanto, ressalta-se que o material é um auxílio para o esclarecimento dos conceitos selecionados, permanecendo o docente como mediador entre os alunos não videntes e o conteúdo.

\section{CONSIDERAÇÕES FINAIS}


A pesquisa teórica revelou que a inclusão de alunos com NEE também ocorre pelos recursos didáticos utilizados em aula. $\mathrm{E}$ cabe aos desenvolvedores, além dos docentes, atentar-se a adequação do ambiente educacional às características de todos os seus participantes. Sendo que a inclusão escolar bem sucedida implica exatamente na participação de todos os alunos no processo de ensino-aprendizagem.

Para tanto, atender às diferentes condições sensoriais, cognitivas ou físicas, são necessários sistemas educacionais que ofereçam cada vez mais respostas adequadas às diversas características e necessidades desses alunos.

Tendo em vista, que atribuir somente ao docente tal tarefa, consideradas as condições atuais do ensino no país, é sobrecarregar o profissional que já possui uma rotina muito desgastante. Destaca-se que outros profissionais, como o designer, podem constituir parcerias com os docentes visando desenvolver soluções para a educação inclusiva.

No caso dos DV, o desafio é ainda mais presente, uma vez que a prática docente precisa se ajustar às diferentes maneiras de comunicação de conteúdo, além da tradicional visão. Nessa situação, o contato com o mundo físico é bem específico, e a explicação de conteúdos abstratos demanda novas estratégias. Principalmente quando considerado que grande parte da dificuldade no ensino dos alunos com DV deriva do fato de que a maioria dos recursos didáticos utilizados no ensino regular tem como base o referencial perceptual da visão.

Entende-se, que o tema aqui abordado brevemente merece aprofundamento, dada a sua importância e complexidade. Essa reflexão proposta pretende despertar mais designers para essa grande demanda para criação de recursos didáticos mais adequados aos diversos perfis dos alunos com NEE.

Por fim, o projeto apresentado será testado em aula e rediscutido, para que, em conjunto com os alunos não videntes e videntes, continuem as contribuições no sentido de melhorar o ensino inclusivo, a cada nova reflexão.

\section{REFERÊNCIAS}

ARAGÃO, A. S; SILVA, V. C; SILVA G. M; Análise da produção em Educação Especial e Inclusiva nos Programas de Pós-Graduação em Ensino de Ciências e Matemática. In: ENCONTRO NACIONAL DE ENSINO DE QUÍMICA, 14., 2008, Curitiba. Anais... Curitiba: UFPR, 2008.

BORGES, G. L. A. Formação de Professores de Biologia, Material Didático e Conhecimento Escolar. 2000. 436f. Tese (Doutorado) - Universidade Estadual de Campinas, curso de Pós-graduação em Educação.

BRASIL. Casa Civil. Decreto n. 6.571 de 17 de set de 2008: Dispõe sobre o financiamento do atendimento educacional especializado na rede pública de ensino regular. Brasília: 17 set. 2008. Disponível em: <http://www.planalto.gov.br/ ccivil_03/_ato2007-2010/2008/Decreto/D6571.htm> Acesso em: 15 jan. 2013.

. Casa Civil. Decreto n. 7.611 de 17 de nov de 2011: Dispõe sobre a educação especial, o atendimento educacional especializado e dá outras providências. Brasília: 17 nov. 2011. Disponível em: <http://www.planalto.gov.br/ccivil_03/_Ato20112014/2011/Decreto/D7611.htm\#art11> Acesso em: 15 jan. 2013. 
Casa Civil. Lei n. 9.394 de 20 de dez de 1996: Estabelece as diretrizes e bases da

educação nacional. Brasília: 20 dez. 1996. Disponível em: <http://www.planalto.gov.br/ccivil_03/leis/19394.htm> Acesso em: 15 jan. 2013.

BRASIL. Conselho Nacional de Educação. Câmara de Educação Básica. Resolução n. 2 de 11 de setembro de 2001: Institui Diretrizes Nacionais para a Educação Especial na Educação Básica. Brasília: CNE/CEB, 2001. Disponível em: <http://portal.mec.gov.br/ cne/arquivos/pdf/CEB0201.pdf>. Acesso em: 16 jan. 2013.

. Conselho Nacional de Educação. Câmara de Educação Básica. Resolução n. 4 de 2 de outubro de 2009: Institui Diretrizes Operacionais para o Atendimento Educacional Especializado na Educação Básica, modalidade Educação Especial. Brasília: CNE/CBE, 2009. Disponível em: <http://peei.mec.gov.br/arquivos/Resol_4_2009_CNE_CEB.pdf >. Acesso em: mar. 2011.

BRASIL. Ministério da Educação. Secretaria de Educação Especial. Política nacional de educação especial na perspectiva da educação inclusiva. Brasília: MEC/SEESP, 2007. Disponível em: <http://peei.mec.gov.br/arquivos/politica_nacional_educacao_ especial.pdf>. Acesso em: 15 jan. 2013.

- Ministério da Educação. Secretaria de Educação Fundamental. Secretaria de Educação Especial. Parâmetros Curriculares Nacionais: adaptações curriculares: estratégias para a educação de alunos com necessidades educacionais especiais. Brasília: MEC/SEF/SEESP, 1998. Disponível em: <http://www.conteudoescola. com.br/pcn-esp.pdf>. Acesso em: 15 jan. 2013.

BRAZ, A; DUARTE, M; CIA, F. Na escola: Adaptação do conteúdo de ciências para os alunos com Síndrome de Down: um relato das ações do PIBID do curso de Licenciatura em Educação Especial. In: CONGRESSO BRASILEIRO DE EDUCAÇÃO ESPECIAL, 5., 2012. Anais... São Carlos: UFSCar, 2012.

CAMARGO, E. P.; NARDI, R. Planejamento de atividades de ensino de Física para alunos com deficiência visual: dificuldades e alternativas. In: REVISTA ELECTRÓNICA DE ENSEÑANZA DE LAS CIENCIAS, v. 6, n. 2, p. 378-401, 2007.

CAMARGO, E. P.; NARDI, R.; VERASZTO, E. V. A comunicação como barreira à inclusão de alunos com deficiência visual em aulas de óptica. In: REVISTA BRASILEIRA DE ENSINO DE FÍSICA, v. 30, n. 3, 2008.

COUTINHO, S. G.; LOPES, M. T.; CADENA, R. A. Ensina Design: mapeamento do uso da linguagem gráfica no ensino fundamental brasileiro. In: CONGRESSO INTERNACIONAL DE DESIGN DA INFORMAÇÃO, 5., 2011, Florianópolis. Anais... Bauru: SBDI, 2011.

COUTO, R.; PORTUGAL, C. Especialização de Design de Material Didático. In: CONGRESSO INTERNACIONAL DE DESIGN DA INFORMAÇÃO, 5., 2011, Florianópolis. Anais... Bauru: SBDI - Sociedade Brasileira de Design da Informação, 2011.

DE VITTA, F. C. F; DE VITTA, A; MONTEIRO A. S. R. Percepção de professores de educação infantil sobre a inclusão da criança com deficiência. In: REVISTA BRASILEIRA DE EDUCAÇÃO ESPECIAL, Marília, v.16, n.3, p. 415-428. Set./Dez. 2010.

GARCIA, R. M. C. Política de educação especial na perspectiva inclusiva e a formação docente no Brasil. In: REVISTA BRASILEIRA DE EDUCAÇÃO, v. 18, n. 52, 2013. 
LOPES, N. R.; ALMEIDA, L. A.; AMADO, M. V. Produção e análise de recursos didáticos para ensinar alunos com deficiência visual o conteúdo de mitose: uma prática pedagógica no ensino de ciências biológicas. In: REVISTA ELETRÔNICA DEBATES EM EDUCAÇÃO CIENTÍFICA E TECNOLÓGICA, v. 2, n. 02, 2014.

MARTI, M. A. S. Didáctica multisensorial de las ciências. Barcelona: Ediciones Paidós Ibérica, 1999.

MIRANDA, V. H. M. O professor de Ciências e Biologia e a inclusão escolar: quais são os obstáculos encontrados até a fonte do saber? 2014. Relatório de conclusão de Iniciação Científica, Instituto de Biociências da Universidade Estadual Paulista "Júlio de mesquita Filho", Botucatu.

PEREIRA, M. K. S. Ensino de geometria para alunos com deficiência visual: análise de uma proposta de ensino envolvendo o uso de materiais manipulativos e a expressão oral e escrita. 2012. 186f. Dissertação (Mestrado) - Universidade Federal de Ouro Preto, curso de Pós-graduação em Educação Matemática.

SANT'ANA, I. M. Educação Inclusiva: concepções de professores e diretores. In: PSICOLOGIA EM ESTUDO, Maringá, v. 10, n. 2, p. 227-234, 2005.

TEODORO, N. C. A Inclusão Escolar e o Ensino de Ciências e Biologia: A visão dos alunos. 2014. Relatório de conclusão de Iniciação Científica, Instituto de Biociências da Universidade Estadual Paulista "Júlio de Mesquita Filho", Botucatu.

UNESCO. Declaração de Salamanca. Sobre Princípios, Políticas e Práticas na Área das Necessidades Educativas Especiais. In: CONFERÊNCIA MUNDIAL DE EDUCAÇÃO ESPECIAL. Salamanca: UNESCO, 1994. Disponível em: <http://portal.mec.gov.br/ seesp/arquivos/pdf/salamanca.pdf> Acesso em: 13 jan. 2013.

VAZ, J. M. C.; PAULINO, A. L. S; BAZON, F. V. M.; KILL, K. B; ORLANDO, T. C; REIS, M. X. Material Didático para Ensino de Biologia: Possibilidades de Inclusão. In: REVISTA BRASILEIRA DE PESQUISA EM EDUCAÇÃO EM CIÊNCIAS, v. 12, n. 3, 2012.

YOSHIKAWA, R. C. S. Possibilidades de aprendizagem na elaboração de materiais didáticos de Biologia com educandos deficientes visuais. 2010. 149 f. Dissertação (Mestrado) - Faculdade de Educação da Universidade de São Paulo, curso de Pósgraduação em Ensino de Ciências.

\section{AGRADECIMENTOS}

Trabalho desenvolvido com o apoio da CAPES. 